\title{
BANDING GREAT HORNED OWLS IN FARMLAND IN THE WEYBURN AREA IN 2003
}

MARTIN BAILEY, 102-1833 Coteau Avenue, Weyburn, SK

Because of time and money restraints, bird banders in Saskatchewan have little opportunity to visit potential nest sites more than once a season to band young. Therefore, they must choose the best weekend to band and, traditionally for Great Horned Owls, that has been the long weekend in May.

Not surprisingly then, when John Whitell first dragged me out on March 29, 2003 to look for Great Horned Owl nests near Weyburn, I had no idea of the numbers of owls that we would see from then to when the last nest site was visited on June 6 . Nor did I anticipate that we would go back a minimum of three times to all locations where we had found owls but no nests.

Historically, the area around Weyburn was shortgrass prairie with few if any trees. Today the landscape surrounding Weyburn is dominated by cereal grain and a mixture of native and introduced grasses. Much smaller plots of land containing occupied and abandoned farmyards consist of grasses, Carragana shrubs and planted trees such as spruce, Plains Cottonwood and elm. One bird to take advantage of this habitat has been the Great Horned Owl and it was in the farmyards in the sea of planted grain that we looked for active Great Horned Owl nests.
In an area bounded approximately by $\mathrm{N} 49^{\circ} 40^{\prime}$ to $\mathrm{N} 49^{\circ} 15^{\prime}$ and $\mathrm{W} 104.00$ to $\mathrm{W}$ $104^{\circ} 30^{\prime}$ (six townships in size) 19 nests were found. Seventeen were successful. Ten single and two pairs of owls were seen at 12 other locations. Repeated attempts made to find occupied nests in these 12 other locations were unsuccessful.

In one of the two nests that failed, an owlet with its egg tooth still evident was found on the ground below the nest site. The nest had been a resting place for a Fox Squirrel. The nest proved too flimsy for its new residents and its bottom had fallen out. Two cracked eggs were found at the other failed nest site.

All birds at active nests located by Johnnie and myself - as well as by others in the Weyburn area - were banded by Kelly Kozij. Unwittingly, our informal but frequent excursions each week in the Weyburn area and the willingness of Kelly Kozij to band continuously from May 11 until June 6, provided us with a data base that allows us to make a number of tentative conclusions.

The first of these is that the traditional banding weekend for Great Horned Owls in Saskatchewan, the long weekend in May, does fall within the best time to 
band owlets in southern Saskatchewan. Kelly estimated the ages of the chicks by plumage and the practical consideration that under two weeks of age Great Horned Owl chicks' legs are too thin to hold a band on them.

Age information became the basis for inferring that the hatching of 90 to 95 percent of all owlets occurred over a three week period beginning April 27 continuing on to May 17. Great Horned Owl incubation lasts between 30 and 37 days, hence it is assumed that sitting on eggs could not have occurred before March 23.' It is likely that between March 23 and the end of April, over 90\% of all owlets that could be banded will be banded. While Great Horned Owls are known to lay a second clutch if the first is destroyed, this is not a certainty. ${ }^{3}$ We had evidence this year that there was only one successful second attempt at laying a second clutch: two owlets that were banded on June 5 at approximately two and half weeks of age. They were the results of a second laying after the first eggs laid at that nesting location were crushed by farm equipment.

While the literature states that single owls are assumed to be immature birds living on the periphery of established territories of breeding pairs, there was no evidence that non-breeders were at a disadvantage in our banding territory. ${ }^{2}$ There were no visible differences in either size or habitat between the twelve locations where non-breeders were and the sites where nesting pairs had taken up residence. In this manmade topography, habitat suitable for Great Horned Owls was separated by miles of unsuitable habitat: cereal grain and grasslands vegetation. Breeding and non-breeding birds were, by default, kept apart by man-made barriers.

Were there actually ten different single birds and two different pairs in the locations where they were noticed? Or is it possible that the single birds and the non-nesting pairs could be subjected to double counting? Often a single bird would be found at one location and none would be noticed that day at other sites within five to ten miles. As the literature states, non-breeding owls are neither sedentary nor territorial which would confirm the suspicion that some of the non-breeding birds were being double counted. ${ }^{1,2}$ This suspicion was reinforced by Rohner's (1997) work on the territorial behaviour of nonbreeding birds in the boreal forests of the Yukon. Rohner concluded that the non-breeding birds ranged over an area that was five times larger than that of breeders. However, this did not mean that 'floaters,' as he calls non-breeders, did not have an affinity for specific territories similar in size to those used by breeding birds. ${ }^{4}$

Were our floaters disadvantaged birds - birds who had not been able to breed for one reason or another? Rohner (1996) found this was the case in times of low numbers of prey species. It was the floaters that had higher mortality rates when food was scarce. ${ }^{5}$

Intuitively this is hard to imagine in the islands of planted trees on grass and grain plains surrounding Weyburn. If anything, non-breeding birds would have more opportunities to pursue game 
than breeding birds who must stay close to and defend a nesting site - a nest site not necessarily of the owls' choosing since Great Horned Owls do not make their own nests but occupy what is available. From that site they then seek out prey species for themselves and their owlets. So, while mated birds may be more aggressive than non-breeding birds, they could easily be situated in an island with less food than one that is nearby with no nest sites but more food.

At present this question of non-breeding birds actually being at an advantage to mating pairs will remain beyond the scope of our excursions into man-made Great Horned Owl territory on the open plains. But it is a tantalizing thought suitable for further investigation.

\section{Acknowledgments}

Many thanks to the landowners who let us on their land.

1. HOUSTON, C.S., D.G. SMITH and C. ROHNER.1998. Great Horned Owl (Bubo virginianus). In The Birds of North America, No. 372 (A. Poole and F. Gill,eds.). The Birds of North America, Inc., Philadelphia, PA.

2. del HOYO, J., A. ELLIOTT and J. SARGATAL, eds. 1999. Handbook of the Birds of the World. Lynx Edicions, Barcelona.

3. JOHNSGARD, Paul A. North American Owls. Smithsonian Institution Press (1988) Washington, D.C.

4. ROHNER, C. 1996. The numerical response of great horned owls to the snowshoe hare cycle: consequences of non-territorial 'floaters' on demography. Journal of Animal Ecology 65: 359-370.

5. ROHNER, C.1997. Non-territorial 'floaters' in great horned owls: space use during a cyclic peak of snowshoe hares. Animal Behavior 53: 901-912.

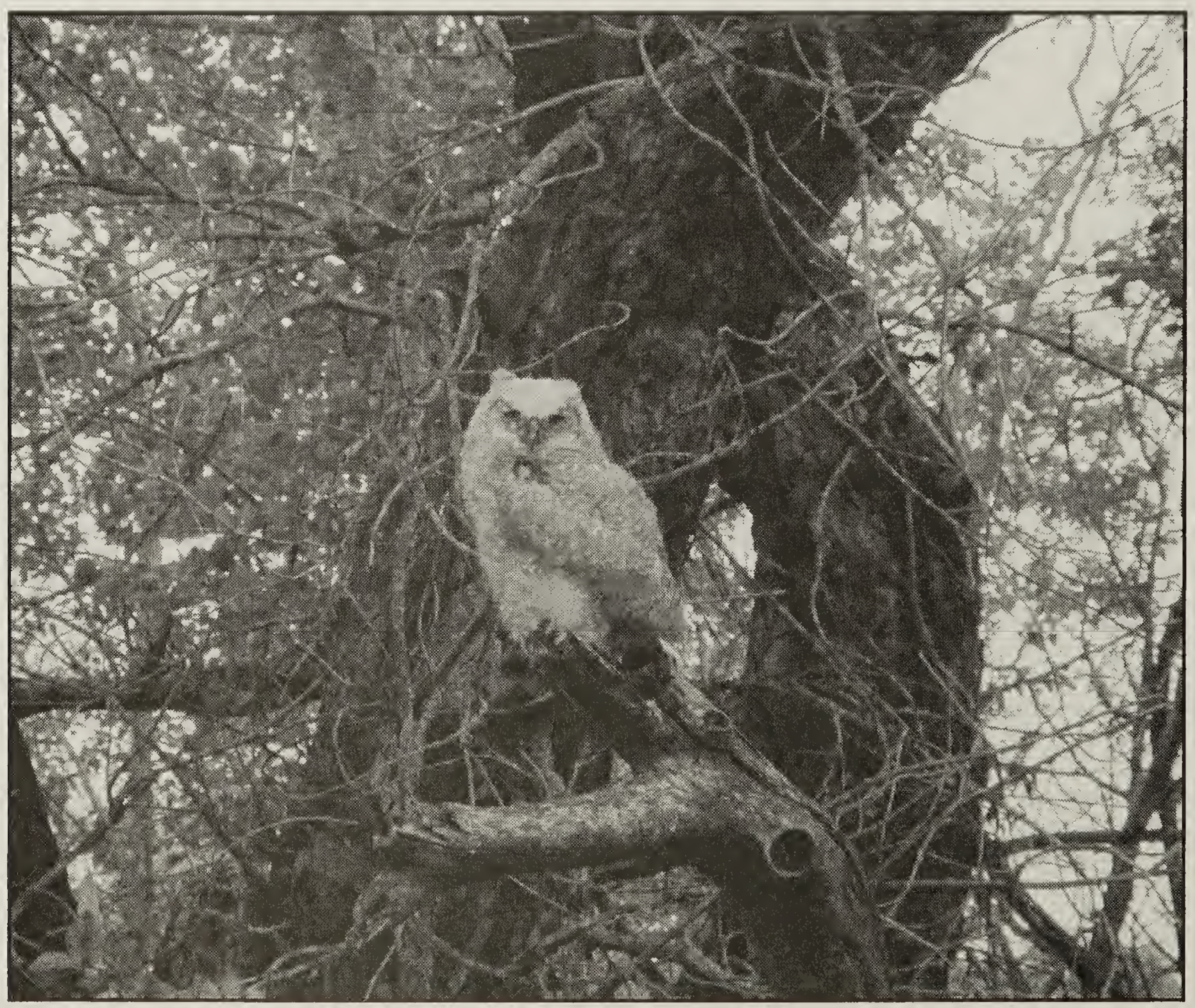

